EXTENDED REPORT

\title{
Similar prediction of mortality by the health assessment questionnaire in patients with rheumatoid arthritis and the general population
}

\author{
T Sokka, A Häkkinen, E Krishnan, P Hannonen
}

Ann Rheum Dis 2004;63:494-497. doi: 10.1136/ard.2003.009530

See end of article for authors' affiliations .....................

Correspondence to: Dr Tuulikki Sokka, Vanderbilt University/ Rheumatology, 203 Oxford House, Nashville, TN 37232-4500, USA; tuulikki.sokka@ vanderbilt.edu

Accepted 21 July 2003

\begin{abstract}
Background: The self report health assessment questionnaire $(\mathrm{HAQ})$ quantifies disability in activities of daily living (ADL). In patients with rheumatoid arthritis, the HAQ predicts mortality, work disability, and hip replacement surgery. It has been widely used in rheumatology, but population based data are rare. Objective: To determine whether the $H A Q$ predicts mortality in patients with rheumatoid arthritis $(n=1095)$ and community controls $(n=1490)$.

Methods: A mailed questionnaire including the $\mathrm{HAQ}$, visual analogue scales for pain and global health, comorbidities, education level, height, weight, and smoking status was administered in June 2000. Two years later, the vital status of the subjects was ascertained from the Finnish Population Register database. Results: There were 41 deaths $(10.1 \%)$ among the 404 patients with rheumatoid arthritis who had a baseline $H A Q \geqslant 1$ (indicating at least some difficulty in most $A D L$ ), and $16(2.3 \%)$ among 691 patients with $\mathrm{HAQ}<1(\mathrm{p}<0.001)$; in the community controls the values were $20(13.6 \%)$ among 147 with $\mathrm{HAQ} \geqslant 1$, and $14(1.0 \%)$ among 1343 with $\mathrm{HAQ}<1 \quad(p<0.001)$. A higher $\mathrm{HAQ}$ score was an independent predictor of mortality in patients with rheumatoid arthritis (hazard ratio $2.73195 \%$ confidence interval, 1.86 to 4.02 ); $p<0.001$ ) and in community controls (2.75 (1.61 to 4.70$) ; p<0.001$ ).

Conclusions: The HAQ predicts mortality in the community population as well as in patients with rheumatoid arthritis. People with similar levels of disability appear to have a similar likelihood of mortality over two years.
\end{abstract}

$\mathrm{S}$ everal self report questionnaires have been constructed over the past decades for use in clinical practice and research, health policy evaluation, and general population surveys. ${ }^{1}$ These questionnaires allow quantitative assessment of concepts such as pain, fatigue, difficulties in daily activities, and psychological distress, which cannot be measured directly by physical methods such as laboratory tests, radiographs, electrocardiograms, and other high technology applications. ${ }^{2}$

The generic health status questionnaires, which were developed for use in many types of disease, have remained largely in the hands of researchers. They are valuable research tools but are rarely incorporated into routine medical care, mainly because of their length and complex scoring systems. Furthermore, self report questionnaires are regarded "subjective," while "objective" high technology data are thought to provide the best information for clinical decision making, monitoring, and prognosis.

In rheumatology, the most widely used self report questionnaires are the health assessment questionnaire (HAQ), ${ }^{3}$ and its modified version the MHAQ, ${ }^{4}$ which were developed to measure disability in daily activities in patients with rheumatoid arthritis. The HAQ is a valuable tool in routine clinical care, as more accurate information about a patient's current functional status is derived from a self report than from laboratory, imaging, or other tests. Furthermore, the HAQ has been shown to predict severe outcomes of rheumatoid arthritis such as mortality and work disability-aspects recently reviewed by $\mathrm{us}^{5}{ }^{6}$ - as well as hip replacement surgery. ${ }^{7}$ The self report of disability in daily activities also predicted mortality in patients with systemic sclerosis, ${ }^{8}$ congestive heart failure, ${ }^{9}$ and cancer. ${ }^{10}$
Few data are available concerning the HAQ at a population level. We therefore undertook a cross sectional survey to compare the HAQ scores in patients with rheumatoid arthritis with those in control subjects living in the same district. ${ }^{11} 12$ Two years after the initial survey, the vital status of the subjects was ascertained from a database at the Population Register Centre of Finland to determine whether the HAQ predicted mortality in the general population over that period.

\section{METHODS \\ Location}

The Central Finland District is located in the southern part of Finland. Its population of 263869 (in the year 2000) is 5\% of the total population of Finland.

\section{Patients with rheumatoid arthritis}

Jyväskylä Central Hospital is the only rheumatology centre in the Central Finland District. All new patients with rheumatoid arthritis are referred to this centre for diagnostic studies and initiation of treatment. Most patients with severe rheumatoid arthritis visit the outpatient or inpatient clinic regularly. The Central Finland rheumatoid arthritis database includes demographic measures, treatments, and outcomes of all patients with rheumatoid arthritis seen in the clinic since January 1993. It is updated daily by a research nurse. By June 2000, the database contained 1763 patients, 1495 of

Abbreviations: $A D L$, activities of daily living; $H A Q$, health assessment questionnaire; VAS, visual analogue scale 
whom were still alive. These 1495 patients were mailed a questionnaire. The questionnaire results were entered into the rheumatoid arthritis database and analysed along with the patient's disease characteristics and treatments.

\section{Controls}

To obtain a population sample, the names and addresses of 2000 people who were at least 30 years old and living in the district were requested from the Ministry of Social Affairs and Health. The sample was drawn from the Population Registry database that includes a personal identification code, date of birth, demographic data, name, and address of all individuals living in Finland. The population sample was designed to have a mean age of 55 years and to include $70 \%$ women, so as to be similar to the rheumatoid population, but was otherwise random. The sampling was done by Statistics of Finland. This organisation operates administratively under the Ministry of Finance but is fully and independently responsible for its statistics. Statistics of Finland obtains the majority of the data from diverse administrative registers, and produces two thirds of all government statistics in Finland (www.stat.fi).

\section{Study design}

A questionnaire was mailed to the 1495 patients with rheumatoid arthritis and the 2000 controls in June 2000. A reminder was sent eight weeks later to non-responder controls.

Functional status in activities of daily living was assessed by the Finnish version of the HAQ, ${ }^{13}$ and included 20 questions in eight categories: dressing, rising, eating, walking, grooming, reaching, gripping, and performing errands. The response alternatives available were 0 , no difficulty; 1 , some difficulty; 2 , much difficulty; 3 , unable to do. The sum of the highest response in each category was divided by 8 to form a score from 0 to 3 . Perceived pain and global status were assessed on a $100 \mathrm{~mm}$ visual analogue scale (VAS).

Information on the presence of comorbidities was sought, including hypertension, coronary artery disease, other heart disease, asthma, chronic bronchitis, chronic kidney disease, peptic ulcer, inflammatory bowel disease, diabetes, thyroid disease, cancer, epilepsy, stroke, Parkinson's disease, psoriasis, chronic leg ulcers, ankylosing spondylitis, osteoarthritis, fibromyalgia, chronic back pain, musculoskeletal trauma, mental illness, and alcoholism. The number of comorbidities was calculated as a plain sum of these conditions.
Other data collected included date of birth, height and weight for body mass index $\left(\mathrm{BMI} ; \mathrm{kg} / \mathrm{m}^{2}\right)$, sex, length of education, and information on smoking status.

\section{End point measurements}

Two years after administration of the questionnaire, the vital status of the subjects was ascertained from a database in the Population Register Centre of Finland, using personal identification codes, which have been used in all population registers in Finland since 1967.

\section{Statistical analysis}

Data analyses were done using SPSS 11.0 (SPSS Inc, Chicago, Illinois, USA) and STATA 7.0 software (STATA Corporation, College Station, Texas, USA). The results for continuous variables are given as mean (SE), and for dichotomous variables as percentages. The differences among the groups were computed by $\chi^{2}$ tests (for dichotomous data) or Student's two tailed $t$ test (for continuous data) for independent samples, as appropriate.

Univariate and multivariate Cox regression models were used to explore the association of risk factors with mortality, which were computed separately for patients with rheumatoid arthritis and for the community controls. In each case the final model included variables that were significant in univariate analysis, adjusted for age and sex (data not shown). Thus in patients with rheumatoid arthritis the final model included disease duration, rheumatoid factor status, HAQ, VAS for pain and global status, number of comorbidities, age, and sex as covariates. In the community controls the final model included VAS for pain and global status, HAQ, age, and sex. The Cox regression model was used to compare the mortality in patients with rheumatoid arthritis with community controls, adjusted for age, sex, and HAQ score.

Kaplan-Meier survival curves were used to illustrate mortality according to the response to the HAQ in four groups: patients with rheumatoid arthritis with a HAQ score of $\geqslant 1$; patients with rheumatoid arthritis with a HAQ score of $<$; ; community controls with a HAQ score of $\geqslant 1$; and community controls with a HAQ score of $<1$. A cut off point of 1 (on the scale of $0-3$ of the HAQ) was chosen as it is clinically relevant and indicates at least some difficulty in most of the activities of daily living.

The study was approved by the ethics committee of Jyväskylä Central Hospital, and Population Register Centre of Finland.

Table 1 Comparison of demographic and questionnaire data at baseline in patients with rheumatoid arthritis and in community controls according to their response to the $H A Q$ questionnaire $(H A Q<1 \vee H A Q \geqslant 1)$

\begin{tabular}{|c|c|c|c|c|c|c|c|c|c|}
\hline \multirow[b]{2}{*}{ Variable } & \multicolumn{4}{|c|}{ Patients with rheumatoid arthritis } & \multicolumn{4}{|c|}{ Community controls } & \multirow{2}{*}{$\begin{array}{l}\text { All subjects: } p \text { value } \\
\text { for patients with RA v } \\
\text { controls }\end{array}$} \\
\hline & $\begin{array}{l}\mathrm{HAQ}<1 \\
(n=691)\end{array}$ & $\begin{array}{l}H A Q \geqslant 1 \\
(n=404)\end{array}$ & $\begin{array}{l}\text { Total } \\
(n=1095)\end{array}$ & p Value & $\begin{array}{l}\mathrm{HAQ}<1 \\
(\mathrm{n}=1343)\end{array}$ & $\begin{array}{l}H A Q \geqslant 1 \\
(n=147)\end{array}$ & $\begin{array}{l}\text { Total } \\
(n=1490)\end{array}$ & p Value & \\
\hline Age (years) & $62.1(0.5)$ & $66.3(0.6)$ & $62.4(0.4)$ & $<0.001$ & $53.7(0.4)$ & $72.1(1.2)$ & $55.5(0.4)$ & $<0.001$ & $<0.001$ \\
\hline Sex ( $\%$ of female) & $67.9 \%$ & $76.2 \%$ & $71.0 \%$ & 0.003 & $71.2 \%$ & $81.0 \%$ & $72.1 \%$ & 0.012 & 0.456 \\
\hline $\begin{array}{l}\text { Duration of rheumatoid } \\
\text { arthritis (years) }\end{array}$ & $9.2(0.3)$ & $15.0(0.5)$ & $11.3(0.3)$ & $<0.001$ & & & & & \\
\hline Positive RF (\%) & $64.8 \%$ & $75.3 \%$ & $68.6 \%$ & 0.001 & & & & & \\
\hline Erosions present (\%) & $53.7 \%$ & $70.5 \%$ & $59.9 \%$ & $<0.001$ & & & & & \\
\hline $\mathrm{HAQ}(0-3)$ & $0.32(0.01)$ & $1.71(0.03)$ & $0.83(0.02)$ & $<0.001$ & $0.10(0.01)$ & $1.84(0.05)$ & $0.27(0.02)$ & $<0.001$ & $<0.001$ \\
\hline Pain VAS $(0-100)$ & $23.1(0.7)$ & $50.7(1.1)$ & $33.2(0.7)$ & $<0.001$ & $16.3(0.6)$ & $57.4(2.3)$ & $20.1(0.7)$ & $<0.001$ & $<0.001$ \\
\hline Global VAS (0-100) & $25.0(0.7)$ & $50.1(1.0)$ & $34.1(0.7)$ & $<0.001$ & $18.2(0.5)$ & $58.0(1.8)$ & $22.0(0.6)$ & $<0.001$ & $<0.001$ \\
\hline Number of comorbidities & $1.5(0.1)$ & $2.4(0.1)$ & $1.9(0.1)$ & $<0.001$ & $1.4(0.0)$ & $3.5(0.2)$ & $1.6(0.0)$ & $<0.001$ & $<0.001$ \\
\hline Education (years) & $10.0(0.2)$ & $8.3(0.2)$ & $9.4(0.1)$ & $<0.001$ & $11.1(0.1)$ & $7.8(0.4)$ & $10.9(0.1)$ & $<0.001$ & $<0.001$ \\
\hline Body mass index $\left(\mathrm{kg} / \mathrm{m}^{2}\right)$ & $26.1 \pm 0.2$ & $26.3 \pm 0.3$ & $26.2 \pm 0.1$ & 0.496 & $26.1(0.1)$ & $27.0(0.5)$ & $26.2(0.1)$ & 0.053 & 0.954 \\
\hline Mortality over 2 years, (\%) & $2.3 \%$ & $10.1 \%$ & $5.2 \%$ & $<0.001$ & $1.0 \%$ & $13.6 \%$ & $2.2 \%$ & $<0.001$ & $<0.001$ \\
\hline
\end{tabular}

Results for continuous variables are given as mean (SE), and for dichotomous variables as percentages. Student's two tailed $t$ test was used for continuous variables, and the $\chi^{2}$ test for non-continuous variables.

$H A Q$, health assessment questionnaire; RA, rheumatoid arthritis; RF, rheumatoid factor; VAS, visual analogue scale. 
Table 2 Cox proportional hazards model of possible predictors of mortality over two years in patients with rheumatoid arthritis

\begin{tabular}{llllr}
\hline & \multicolumn{3}{l}{$\begin{array}{l}\text { Hazard } \\
\text { ratio }\end{array}$} & \multicolumn{2}{l}{$\mathbf{9 5 . 0 \%} \mathbf{C l}$} & \\
\cline { 3 - 4 } & & Lower & Upper & p Value \\
\hline Age & 1.05 & 1.01 & 1.08 & 0.004 \\
Sex, male $v$ female & 2.78 & 1.50 & 5.16 & 0.001 \\
Disease duration & 1.03 & 1.00 & 1.06 & 0.071 \\
RF, positive $v$ negative & 3.19 & 1.23 & 8.23 & 0.017 \\
HAQ & 2.73 & 1.86 & 4.02 & $<0.001$ \\
Pain VAS & 0.99 & 0.97 & 1.01 & 0.146 \\
Global VAS & 1.01 & 0.98 & 1.03 & 0.619 \\
Number of comorbidities & 1.23 & 1.05 & 1.44 & 0.010 \\
\hline
\end{tabular}

Model includes variables that were significant in univariate analysis adjusted for age and sex. Complete data were available in 965 patients and are included in the analysis.

$\mathrm{Cl}$, confidence interval; $H A Q$, health assessment questionnaire; RF, rheumatoid factor; VAS, visual analogue scale.

\section{RESULTS}

\section{Patients}

In all, 1095 subjects with rheumatoid arthritis (73\% of 1495) returned a completed questionnaire. The mean age of the respondents was 62.4 years (range 19 to 96), 71\% were female, mean disease duration was 11.3 years, 69\% (of 1013 patients tested) were positive for rheumatoid factor, and $60 \%$ had erosions on radiography of their hands or feet (table 1).

\section{Controls}

In all, 1530 control subjects returned the questionnaire (77\% of 2000), 1490 of whom completed the HAQ. The mean age of the respondents was 55.5 years (range 30 to 91 ), and $72 \%$ were female (table 1).

\section{Mortality}

Over the two year period, the number of deaths was 41 (10.1\%) among 404 patients with rheumatoid arthritis with a baseline HAQ score of $\geqslant 1$, and $16(2.3 \%)$ among 691 patients with a HAQ score of $<1 \quad(p<0.001)$. The corresponding figures for the community controls were 20 (13.6\%) of 147 , and $14(1.0 \%)$ of $1343(\mathrm{p}<0.001)$ (table 1$)$.

In a Cox regression model for the patients with rheumatoid arthritis, a higher HAQ score was an independent predictor of mortality, with a hazard ratio of 2.73 (95\% confidence interval, 1.86 to 4.02$)(\mathrm{p}<0.001)$. Other independent predictors of mortality were male sex $(p=0.001)$, older age $(p=0.004)$, number of comorbidities $(p=0.010)$, and positive rheumatoid factor $(p=0.017)$ (table 2 ). In the

Table 3 Cox proportional hazards model of possible predictors of mortality over two years in community controls

\begin{tabular}{lllll}
\hline & & \multicolumn{2}{l}{$\mathbf{9 5 . 0 \%} \mathbf{C l}$} & \\
\cline { 3 - 4 } & Hazard & & \\
& ratio & Lower & Upper & p Value \\
\hline Age & 1.03 & 0.99 & 1.06 & 0.126 \\
Sex, male v female & 1.65 & 0.71 & 3.87 & 0.248 \\
HAQ & 2.75 & 1.61 & 4.70 & $<0.001$ \\
Pain VAS & 0.99 & 0.97 & 1.01 & 0.987 \\
Global VAS & 1.03 & 1.00 & 1.05 & 0.029 \\
\hline
\end{tabular}

Model includes variables that were significant in univariate analysis adjusted for age and sex. Complete data were available in 1379 subjects and are included in the analysis.

$\mathrm{Cl}$, confidence interval; $\mathrm{HAQ}$, health assessment questionnaire; VAS, visual analogue scale.
Table 4 Cox proportional hazards model of mortality over two years in patients with rheumatoid arthritis and community controls

\begin{tabular}{llllll}
\hline & & \multicolumn{2}{l}{$\mathbf{9 5 . 0 \%} \mathrm{Cl}$} & \\
\cline { 4 - 4 } & Hazard & & \\
& ratio & Lower & Upper & p Value \\
\hline Age & 1.05 & 1.03 & 1.07 & $<0.001$ \\
Sex, male $v$ female & 2.54 & 1.65 & 3.91 & $<0.001$ \\
$\mathrm{HAQ}$ & 2.89 & 2.27 & 3.67 & $<0.001$ \\
RA $v$ controls & 1.19 & 0.77 & 1.83 & 0.441 \\
\hline
\end{tabular}

Complete data were available in 1095 patients with rheumatoid arthritis and 1490 community controls and are included in the analysis. $\mathrm{Cl}$, confidence interval; $H A Q$, health assessment questionnaire; $R A$, rheumatoid arthritis.

community controls, a higher HAQ score was an independent predictor of mortality, with a hazard ratio of 2.75 (1.61 to 4.70) $(\mathrm{p}<0.001)$ (table 3$)$.

Patients with rheumatoid arthritis were more likely to die over two years than the community controls in an unadjusted analysis (table 1). In a Cox regression model adjusted for age and sex, mortality in patients with rheumatoid arthritis was also higher than in the community controls $(p=0.027$, data not shown). However, when the functional capacity of the subjects was included in the model, having rheumatoid arthritis was not an independent predictor of mortality (table 4), which indicates that similar levels of disability are associated with similar likelihood of mortality, regardless of having rheumatoid arthritis.

Figure 1 shows the Kaplan-Meier estimates of the probability of death in patients with rheumatoid arthritis and community controls, according to the baseline HAQ score. Subjects with higher HAQ scores of $\geqslant 1$ had the worst prognosis in both of the groups.

\section{DISCUSSION}

HAQ scores have been shown to predict severe outcomes of rheumatoid arthritis including mortality, work disability, and joint replacement surgery. ${ }^{5-7}$ Our study confirms previous reports that the HAQ predicts mortality in patients with rheumatoid arthritis. However, the novel finding of our study is that the HAQ also predicts mortality in the general population. In the Cox regression model, the HAQ appeared to be an independent predictor of death in the general population, with a hazard ratio of 2.75 (1.61 to 4.70 ), similar

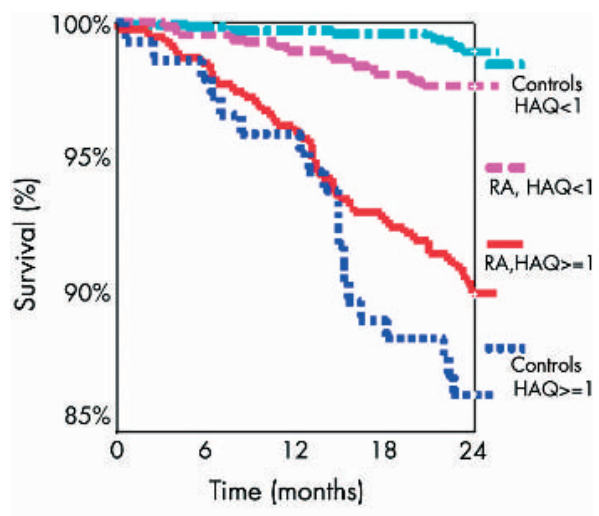

Figure 1 Kaplan-Meier estimates of the probability of death over two years in 1095 patients with rheumatoid arthritis and 1490 community controls according to the $H A Q$ score at baseline $(H A Q \geqslant 1$ indicates at least some difficulties in most activities of daily living). 
to that of patients with rheumatoid arthritis, in whom the hazard ratio was 2.73 (1.86 to 4.02 ). In other words, the risk of death increased 2.7 times for each one point increase in the HAQ score (on a scale of 0 to 3 ) in both groups. Similar levels of disability were associated with a similar likelihood of mortality over two years, regardless of the diagnosis of rheumatoid arthritis (table 4).

The HAQ includes questions concerning the subject's experience in coping with simple activities of daily living. In patients with rheumatoid arthritis, the HAQ has been shown to be associated with pain and psychological variables, and only weakly with radiographic erosion scores or joint deformities. ${ }^{14}{ }^{15}$ Overall, pain and functional loss are weakly associated with laboratory tests and radiographs in any of the chronic musculoskeletal diseases such as osteoarthritis ${ }^{16}$ and chronic low back pain. ${ }^{17}{ }^{18}$ It therefore appears that a self report questionnaire concerning daily activities captures information that is not available from any other source but the patient.

Healthy habits were associated with slow progression of disability and better survival in elderly runners $v$ community controls, ${ }^{19}$ and in university alumni. ${ }^{20}$ In these studies, the progression of disability was measured by the HAQ. The results of the present study are in line with previous findings, and extend the use of the HAQ to apply all people over 30 years of age in the community, while in previous studies the HAQ was applied only in elderly people.

A limitation of our study is that we did not explore the reasons for the baseline disability in depth. No physical examination was undertaken, and no high technology data were obtained. One might also argue that the sickest people die, and the results of the present study do not provide any novel information. Nevertheless, the study shows that a simple and inexpensive one page self report questionnaire regarding activities of daily living, which only takes between one and five minutes to complete, is a feasible tool for predicting mortality at a population level over a two year period, not only in patients with rheumatoid arthritis but also in the general population. The likelihood of dying appears to be similar in people with similar levels of disability according to the HAQ, regardless of whether or not they have rheumatoid arthritis.

\section{ACKNOWLEDGEMENTS}

We thank Ms Sari Leinonen and Mr Jani Saalamo for excellent data management, Ms Leena Miina and Marjo Kortemaki RN for work with the Central Finland rheumatoid arthritis database, and Drs Heikki Miettinen and Theodore Pincus for helpful discussions during the preparation of the manuscript. The study was supported in part by the Academy of Finland.
Authors' affiliations

T Sokka, A Häkkinen, P Hannonen, Jyväskylä Central Hospital, Jyväskylä, Finland

E Krishnan, Clinical Research Center of Reading, West Reading, Pennsylvania, USA

T Sokka, Vanderbilt University Medical School, Nashville, Tennessee, USA

\section{REFERENCES}

1 Kvien TK. Epidemiology of disability in rheumatoid arthritis. Rheumatology 2002;41:121-3.

2 Sokka T. Assessment of pain in patients with rheumatic diseases. Baillieres Best Pract Res Clin Rheumatol 2003;17:427-49.

3 Fries JF, Spitz P, Kraines RG, Holman HR. Measurement of patient outcome in arthritis. Arthritis Rheum 1980;23:137-45.

4 Pincus T, Summey JA, Soraci SA, Wallston KA, Hummon NP. Assessment of patient satisfaction in activities of daily living using a modified Stanford health assessment questionnaire. Arthritis Rheum 1983;26:1346-53.

5 Pincus T, Sokka T. Quantitative target values of predictors of mortality in rheumatoid arthritis as possible goals for therapeutic interventions: an alternative approach to remission or ACR20 responses? J Rheumatol 2001;28:1723-34

6 Sokka T, Pincus T. Markers for work disability in rheumatoid arthritis. J Rheumatol 2001;28:1718-22.

7 Wolfe F, Zwillich SH. The long-term outcomes of rheumatoid arthritis: A 23year prospective, longitudinal study of total joint replacement and its predictors in 1600 patients with rheumatoid arthritis. Arthritis Rheum 1998;41:1072-82.

8 Clements PJ, Wong WK, Hurwitz EL, Furst DE, Mayes M, White B, et al. The Disability Index of the Health Assessment Questionnaire is a predictor and correlate of outcome in the high-dose versus low-dose penicillamine in systemic sclerosis trial. Arthritis Rheum 2001;44:653-61.

9 Konstam V, Salem D, Pouleur H, Kostis J, Gorkin L, Shumaker S, et al. Baseline quality of life as a predictor of mortality and hospitalization in 5025 patients with congestive heart failure. Am J Cardiol 1996;78:890-5.

10 Ringdal GI, Götestam KG, Kaasa S, Kvinnsland S, Ringdal K. Prognostic factors and survival in a heterogeneous sample of cancer patients. Br J Cancer 1996;73:1594-9.

11 Sokka T, Krishnan E, Häkkinen A, Hannonen P. Functional disability in rheumatoid arthritis patients compared with a community population in Finland. Arthritis Rheum 2003;48:59-63.

12 Krishnan E, Sokka T, Hannonen P. Smoking-gender interaction and risk for rheumatoid arthritis. Arthritis Res Ther 2003;5:R158-62.

13 Hakala $M$, Nieminen $P$, Koivisto $O$. More evidence from a community based series of better outcome in rheumatoid arthritis. Data on the effect of multidisciplinary care on the retention of functional ability. J Rheumatol 1994;21:1432-7.

14 Sokka T, Kankainen A, Hannonen P. Scores for functional disability in patients with rheumatoid arthritis are correlated at higher levels with pain scores than with radiographic scores. Arthritis Rheum 2000;43:386-9.

15 Escalante A, Del Rincón I. How much disability in rheumatoid arthritis is explained by rheumatoid arthritis? Arthritis Rheum 1999:42:1712-21.

16 Peat G, Croft P, Hay E. Clinical assessment of the osteoarthritis patient. Baillieres Best Pract Res Clin Rheumatol 2001;15:527-44.

17 Boos N, Lander PH. Clinical efficacy of imaging modalities in the diagnosis of low-back pain disorders. Eur Spine J 1996;5:2-22.

18 Waddell G, Somerville D, Henderson I, Newton M. Objective clinical evaluation of physical impairment in chronic low back pain. Spine 1992;17:617-28.

19 Fries JF, Singh G, Morfeld D, Hubert HB, Lane NE, Brown BW. Running and the development of disability with age. Ann Intern Med 1994; 121:502-9.

20 Vita AJ, Terry RB, Hubert HB, Fries JF. Aging, health risks, and cumulative disability. NEngl J Med 1998;338:1035-41. 